\title{
Heteroses materna e individual para ganho de peso pré-desmama em bovinos Nelore $\times$ Hereford e Nelore $\times$ Angus
}

[Maternal and individual heterosis for preweaning daily gain in Nellore $\times$ Hereford and Nellore $\times$ Angus cattle]

\author{
R.A. Teixeira ${ }^{1}$, L.G. Albuquerque $e^{2,3 *}$ \\ ${ }^{1}$ Doutorando - FCAV - UNESP - Jaboticabal, SP \\ ${ }^{2}$ Departamento de Zootecnia - FCAV - UNESP - Jaboticabal \\ Via de Acesso Prof. Paulo Donato Castellane s/n \\ 14884-900 - Jaboticabal, SP \\ ${ }^{3}$ Pesquisadora do $\mathrm{CNPq}$
}

\begin{abstract}
RESUMO
Foram utilizados dados de 62.985 animais das raças Nelore, Hereford, Angus e produtos de cruzamentos Nelore $\times$ Angus e Nelore $\times$ Hereford de rebanhos comerciais a fim de estimar os efeitos de heterose materna e individual para o ganho médio diário no período pré-desmama (GMD). Os valores obtidos de heterose individual e materna considerando-se o valor médio de GMD da população representam um acréscimo de $6,2 \%$ e $11,2 \%$ no GMD para os animais $\mathrm{F} 1$ e filhos de vacas $\mathrm{F} 1$, respectivamente. A heterose materna correspondeu a $64,5 \%$ da heterose total. Animais cruzados Bos taurus $\times$ Bos indicus obtêm GMD maior do que o dos animais das raças puras.
\end{abstract}

Palavras-chave: bovinos de corte, cruzamento, efeito aditivo, efeito não aditivo

\begin{abstract}
Data on 62.985 Nellore, Hereford, Angus and Nellore $\times$ Angus and Nellore $\times$ Hereford crossbred calves were analyzed to estimate maternal and individual heterosis for preweaning daily weight gain (PWD). The individual and maternal heterosis of average daily weight gain showed improvements of 6.2 and $11.2 \%$ for PWD of F1 calves and for calves borne from F1 dams. Maternal heterosis corresponded to $64.5 \%$ of total heterosis. Bos taurus $\times$ Bos indicus crossbred cattle have a PWD larger than the average of purebred cattle.
\end{abstract}

Keywords: beef cattle, crossbreeding, additive effect, non-additive effect

Recebido para publicação em 21 de fevereiro de 2003

Recebido para publicação, após modificações, em 13 de agosto de 2004

*Autor para correspondência (corresponding author)

E-mail: rodrigot@fcav.unesp.br 


\section{INTRODUÇÃO}

Os cruzamentos entre raças de gado de corte têm recebido especial atenção por parte dos pecuaristas brasileiros. A crescente utilização da inseminação artificial e a confiança em usar algumas raças compostas são alguns dos fatores que despertaram o interesse em explorar as vantagens dos cruzamentos para as características de produção. A combinação de cruzamentos e a seleção permitem a obtenção de animais eficientes nos mais diversos ambientes e em condições de atender, com flexibilidade, às exigências do mercado consumidor. Os índices de produção total podem aumentar em até 10$20 \%$ com os benefícios dos cruzamentos entre raças Bos taurus, em ambientes favoráveis, e em $30-50 \%$ nos cruzamentos entre Bos taurus e Bos indicus, em condições climáticas desfavoráveis (Koger et al., 1976). Barbosa e Alencar (1995) sugeriram que o cruzamento entre raças taurinas e zebuínas pode ser uma das estratégias para melhorar os índices produtivos em bovinos de corte.

Os principais programas de melhoramento genético dos países exportadores de carne bovina procuram otimizar sistemas de avaliação genética de populações compostas por várias raças. Porém, um dos obstáculos tem sido a dificuldade em modelar, com precisão, os efeitos genéticos aditivos e, principalmente, os efeitos genéticos não-aditivos. Madalena (2001) descreveu a utilização do modelo aditivodominante que foi usado em animais, pela primeira vez, por Vencovsky (1970). Uma das aplicações clássicas desse modelo foi feita por Dickerson (1973), para medir o desempenho esperado em populações de animais, cruzados, no qual a diferença aditiva entre as raças definese como a diferença entre a média das raças puras, e a heterose como sendo a diferença entre o desempenho da geração F1 e a média das raças parentais.

O objetivo deste trabalho foi estimar as heteroses materna e individual para ganho médio diário de peso no período pré-desmama (GMD), utilizando dados de rebanhos comerciais das raças Angus, Hereford, Nelore e produtos de cruzamento Nelore $\times$ Angus e Nelore $\times$ Hereford.

\section{MATERIAL E MÉTODOS}

Os dados utilizados são provenientes de 62.985 animais, nascidos entre 1974 e 1997, de rebanhos comerciais predominantemente das regiões Sul e Centro-Oeste, que fazem partem dos programas de melhoramento genético da Natura Genética Sul-Americana e Conexão DeltaG.

As fazendas do programa Natura estão distribuídas pelos estados de Tocantins, Goiás, Minas Gerais, Mato Grosso, Mato Grosso do Sul, São Paulo, Paraná e Rio Grande do Sul, com predominância no Mato Grosso do Sul, e caracterizam-se por cadastrar, inicialmente, vacas da raça Nelore e utilizar sêmen e touros Angus e Brangus.

As fazendas do programa DeltaG estão distribuídas pelos estados de Goiás, Mato Grosso, Mato Grosso do Sul, São Paulo e Rio Grande do Sul, com predominância no Rio Grande do Sul, e caracterizam-se por terem rebanhos maiores que os do Natura e possuírem vacas Hereford inseminadas com sêmen de touros Nelore. Assim, as raças envolvidas são Nelore, Angus, Hereford e produtos de cruzamentos de Angus e Hereford com Nelore.

Os dados foram analisados por máxima verossimilhança restrita (Patterson e Thompson, 1971), empregando-se o método não derivativo descrito por Smith e Graser (1986) e Graser et al. (1987). Foi aplicado o modelo animal utilizando o algoritmo desenvolvido por Boldman et al. (1993).

O modelo geral proposto foi:

$\mathrm{y}=\mathrm{X} \beta+\mathrm{Z} a+\mathrm{M} m+\mathrm{W} c+e$, em que:

$y=$ vetor de variáveis dependentes;

$\beta=$ vetor de efeitos fixos;

$a=$ vetor de valores genéticos aditivos dos animais;

$m=$ vetor de valores genéticos aditivos maternos; $c=$ vetor de efeitos de ambiente permanente da

vaca;

$e=$ vetor de efeitos residuais;

$X, Z, M$ e $W$ são matrizes de incidência respectivas para cada efeito.

As pressuposições do modelo foram: 
$\mathrm{E}(y)=X \beta, \mathrm{E}(a)=0, \mathrm{E}(m)=0, \mathrm{E}(c)=0$ e $\mathrm{E}(e)=0$.

$\operatorname{Var}\left[\begin{array}{c}\mathrm{a} \\ \mathrm{m} \\ \mathrm{c} \\ \mathrm{e}\end{array}\right]=\left[\begin{array}{cccc}\mathrm{A} \sigma_{\mathrm{a}}^{2} & \mathrm{~A} \sigma_{\mathrm{am}} & 0 & 0 \\ \mathrm{~A} \sigma_{\mathrm{am}} & \mathrm{A} \sigma_{\mathrm{m}}^{2} & 0 & 0 \\ 0 & 0 & \mathrm{I}_{\mathrm{n}} \sigma_{\mathrm{c}}^{2} & 0 \\ 0 & 0 & 0 & \mathrm{I}_{\mathrm{nb}} \sigma_{\mathrm{e}}^{2}\end{array}\right]$, em que:

$A=$ matriz de parentesco genético aditivo;

$I_{n v}$ e $I_{n b}=$ matrizes identidade de dimensão (nv) número de vacas e (nb) total de observações;

$\sigma_{a}^{2}=$ variância genética aditiva direta;

$\sigma_{m}^{2}=$ variância genética aditiva materna;

$\sigma_{c}^{2}=$ variância de ambiente permanente;

$\sigma_{a m}=$ covariância entre os efeitos genéticos aditivos direto e materno;

$\sigma_{e}^{2}=$ variância residual.

Em geral, a estrutura dos dados provenientes de rebanhos comerciais é inadequada para a estimativa da covariância entre os efeitos genéticos aditivos direto e materno. Admitiu-se que a covariância entre esses efeitos era nula, de acordo com a recomendação de Benyshek et al (1989) e Schaeffer (1996).

Os efeitos fixos considerados foram grupocontemporâneo, definido como fazenda, retiro e grupo de manejo ao nascimento e à desmama, ano de nascimento e sexo do bezerro, e como covariáveis a idade da vaca ao parto, idade do bezerro à desmama e data juliana de nascimento, heterozigose individual (efeito linear), heterozigose materna (efeito linear), fração de genes Angus do bezerro e fração de genes Angus da vaca, fração de genes Hereford do bezerro e fração de genes Hereford da vaca.

A heterose foi estimada pela inclusão dos efeitos de heterozigose materna e individual como covariáveis do modelo. A fim de melhor estimar a heterose, foram incluídas no modelo as covariáveis relacionadas ao efeito da composição racial, Hereford ou Angus, do bezerro e da vaca, que estimam os efeitos aditivos de raça. Assim, para cada observação, foram incluídas quatro colunas, nas quais o valor zero indicaria que o animal e a vaca seriam da raça Nelore. Fez-se uma estimativa única para os efeitos de heterose (materna e individual) para os dois conjuntos de dados, considerando-os como cruzamento Europeu-Zebu.
Como os dois arquivos se complementaram, a análise conjunta das duas populações permitiu obter uma correlação menor entre as colunas de efeito aditivo, uma vez que pelo menos metade das colunas contém zeros. Por exemplo, quando o animal é da raça Angus, as colunas para composição racial Hereford são preenchidas por zero. Também foi observado que tal reunião forneceu tanto maior número de observações dentro de cada composição genética quanto maior foi o número de diferentes composições. Assim, foi obtida melhor estrutura para separar efeitos aditivos dos efeitos de dominância direta e materna, pois a regressão sobre as diferentes composições Europeu-Zebu pode ser realizada com maior número de pontos.

\section{RESULTADOS E DISCUSSÃO}

O valor observado para GMD variou de 0,152 a $1,605 \mathrm{~kg} / \mathrm{dia}$, com média de $0,659 \pm 0,155 \mathrm{~kg} / \mathrm{dia}$.

Os resultados das estimativas dos componentes de variância e herdabilidades são apresentados na Tab. 1.

Tabela 1. Componentes de variância e herdabilidade $\left(\mathrm{h}^{2}\right)$ estimados para a característica ganho médio diário pré-desmama

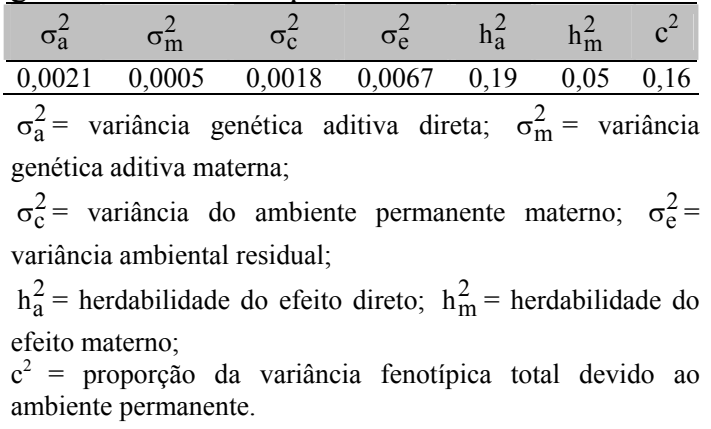

Os resultados indicam a possibilidade de se realizar seleção efetiva para o GMD e assemelham-se aos citados na literatura revisada por Mercadante et al. (1995). Resultados semelhantes também foram obtidos por Meyer et al. (1992), que estimaram, para uma população de animais Hereford, valores de herdabilidade para o efeito direto e efeito materno, 0,19 e 0,13, respectivamente.

As estimativas dos efeitos aditivos e de heterose individuais e maternas são apresentadas na Tab. 2 . 
Considerando o valor médio de GMD da população $(0,659 \mathrm{~kg} / \mathrm{dia})$, a estimativa de heterose individual obtida $(0,041 \mathrm{~kg} / \mathrm{dia})$ representa acréscimo de $6,2 \%$ no GMD para os animais F1. Para os bezerros filhos de vacas
F1, o valor de heterose materna $(0,074 \mathrm{~kg} / \mathrm{dia})$ representa aumento de 11,2\% no GMD médio da população estudada. A heterose materna correspondeu a $64,5 \%$ da heterose total.

Tabela 2. Estimativas dos efeitos aditivos e de heterose individuais e maternas para a característica ganho médio diário pré-desmama

\begin{tabular}{lcccc}
\hline & Aditivo individual & Aditivo materno & Heterose individual & Heterose materna \\
\hline Angus & 0,047 & $-0,022$ & 0,041 & 0,074 \\
Hereford & $-0,025$ & $-0,198$ & 048 \\
\hline
\end{tabular}

Estes resultados foram semelhantes aos de Restle et al. (2000), que obtiveram 9,3\% de heterose para o ganho médio diário de cruzamentos recíprocos das raças Charolesa e Nelore. A mesma tendência foi verificada por Fries et al. (2000), que relataram valores de heterose individual de $9,8 \%$ e heterose materna de $13,1 \%$ para o peso à desmama de animais Braford. Entretanto, Dal-Farra et al. (2002) obtiveram $8,9 \%$ de heterose materna e $9,9 \%$ de heterose individual para o ganho de peso do nascimento à desmama de animais Brangus e Braford.

O efeito aditivo da raça Nelore foi superior ao das raças britânicas, exceto quanto ao efeito aditivo da raça Angus do bezerro (Tab. 2). Existem duas situações que poderiam explicar esse resultado: (1) caso o grupo Natura tenha utilizado touros da raça Angus superiores e (2) caso os rebanhos Nelore do programa da Conexão DeltaG fossem superiores aos utilizados no programa Natura. Provavelmente, ambas as situações ocorreram. Trematore et al. (1998), ao estudarem, entre outras características, o peso à desmama, obtiveram estimativas negativas para os efeitos aditivos maternos da raça Charolesa em relação às estimativas da raça Nelore. Os autores relacionaram-nas ao fato de que, provavelmente, as vacas cruzadas, por terem maior potencial produtivo, também apresentam maiores requisitos nutricionais e, portanto, poderiam apresentar pior desempenho em ambiente mais restritivo.

$\mathrm{Na}$ Tab. 3 apresentam-se as predições, utilizando-se somente as soluções para os efeitos genéticos aditivos e com a média do rebanho como intercepto. Portanto, os valores absolutos não têm significado, mas servem para ilustrar o comportamento do GMD em função somente dos efeitos aditivos e na ausência de outros efeitos genéticos.

Tabela 3. Ganho médio diário pré-desmama predito $(\mathrm{kg} / \mathrm{dia})$ pelos estimadores dos efeitos genéticos aditivos em função da composição racial da vaca e do bezerro e na ausência de outros efeitos genéticos

\begin{tabular}{lcccc}
\hline Composição racial & Bezerro Hereford & Vaca Hereford & Bezerro Angus & Vaca Angus \\
\hline Puro europeu & 0,634 & 0,461 & 0,706 & 0,637 \\
F1 & 0,647 & 0,560 & 0,683 & 0,648 \\
Nelore & & & 0,659 &
\end{tabular}

Neste caso, como era esperado, o desempenho dos animais F1 foi intermediário ao das raças puras, porém, ao incluir o efeito da heterose, os bezerros F1 superaram os das raças puras; o desempenho foi de $0,687 \mathrm{~kg} / \mathrm{dia}$ para os animais Nelore $\times$ Hereford e $0,723 \mathrm{~kg} / \mathrm{dia}$ para os animais Nelore $\times$ Angus.

Outro aspecto raramente abordado em relação à análise de dados de animais cruzados é a esperada correlação entre as covariáveis dos efeitos genéticos aditivos e os efeitos de heterozigose (Tab. 4), uma vez que, no cálculo da heterozigose do indivíduo, entra a composição racial de seus pais. Assim, certo grau de dependência deve ser esperado. Os valores obtidos para as correlações entre os componentes que estimam os efeitos genéticos aditivos e aqueles que estimam a heterose foram altos. Este é um resultado bastante comum nesse tipo de 
análise, como verificado por Rodrigues-Almeida et al. (1997) e Pollak e Quaas (1998).

Tabela 4. Correlação (Pearson) entre as covariáveis genéticas dentro das raças britânicas

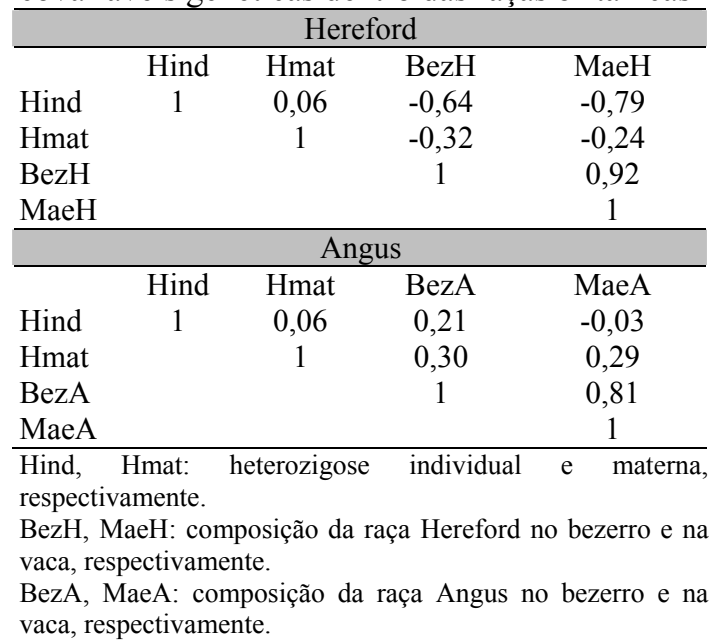

\section{CONCLUSÕES}

Sob as condições deste trabalho, é possível concluir que os valores de herdabilidade confirmam a possibilidade de se realizar efetiva seleção para ganho de peso médio diário prédesmama, que as estimativas de heterose obtidas indicam que os animais cruzados Bos taurus $\times$ Bos indicus obtêm ganho médio diário prédesmama superior à média dos animais das raças puras e que os animais cruzados são uma alternativa interessante como forma de aumentar o desempenho nessa característica.

\section{AGRADECIMENTOS}

Os autores agradecem à empresa GenSys Consultores Associados S/C Ltda. pelo fornecimento dos dados e à FAPESP pelo apoio para execução deste estudo.

\section{REFERÊNCIAS BIBLIOGRÁFICAS}

BARBOSA, P.F.; ALENCAR, M.M. Sistema de cruzamentos em bovinos de corte: estado da arte e necessidades de pesquisa. In: REUNIÃO ANUAL DA SOCIEDADE BRASILEIRA DE
ZOOTECNIA, 32., 1995, Brasília. Anais... Brasília: SBZ, 1995. p.681-683.

BENYSHEK, L.L.; JOHNSON, M.H.; LITTLE, D.E. et al. Application of an animal model in the United States beef cattle industry. J. Anim. Sci., v.71, p.35-53, 1988.

BOLDMAN, K.G.; KRIESE, L.A.; VAN VLECK, L.D. et al. A manual for use of MTDFREML. Clay Center, NE: USDA-ARS, 1993. 120p.

DAL-FARRA, R.A.; ROSO, V.M.; SCHENKEL, F.S. Efeitos de ambiente e de heterose sobre o ganho de peso do nascimento ao desmame e sobre os escores visuais ao desmame de bovinos de corte. Rev. Bras. Zootec., v.31, p.1350-1361, 2002.

DICKERSON, G.E. Inbreeding and heterosis in animals. In: ANIMAL BREEDING AND GENETICS SYMPOSIUM IN HONOR OF Dr. J.L. LUSH, 1973, Champaign. Proceedings... Champaign: ASAS, 1973. p.54-77.

FRIES, L.A.; JOHNSTON, D.J.; HEARNSHAW, H. et al. Evidence of epistatic effects on weaning weight in crossbreed beef cattle. [s.1.]. AGBU - Institute of NSW Agriculture and the University of New England, 2000 .

GRASER, H-U.; SMITH, S.P.; TIER, B.A. Derivative-free approach for estimating variance components in animal models by restricted maximum likelihood. J. Anim. Sci., v.64, p.13621370, 1987.

KOGER, M.; CUNHA, T.J.; WARNICK, A.C. Cruzamientos en ganado vacuno de carne. Montevideo: Hemisferio Sur, 1976. 559p.

MADALENA, F.E. Consideraciones sobre modelos para la predicción del desempeño de cruzamientos en bovinos. Arch. Latinoam. Prod. Anim., v.5, p.97-126, 2001.

MERCADANTE, M.E.Z; LOBO, R.B.; BORJAS, B.R. et al. Parámetros genéticos para características de crecimiento em cebuínos de carne: Una revisión. Arch. Latinoam. Prod. Anim., v.3, p.45-89, 1995.

MEYER, K. Variance components due to direct and maternal effects for growth traits of Australian beef cattle. Livest. Prod. Sci., v.31, p.179-204, 1992. 
PATTERSON, H.D.; THOMPSON, R. Recovery of inter-block information when block sizes are unequal. Biometrika, v.58, p.545-554, 1971.

POLLAK E. J.; QUAAS, R.L. Multibreed genetic evaluations of beef cattle. WORLD CONGRESS ON GENETICS APPLIED TO LIVESTOCK PRODUCTION, 6., 1998. Proceedings..., 1998. v.23, p.81-88.

RESTLE, J.; ALVES FILHO, D.C.; FATURI, C. et al. Desempenho na fase de crescimento de machos bovinos inteiros ou castrados de diferentes grupos genéticos. Rev. Bras. Zootec., v.29, p.1036-1046, 2000.

RODRIGUES-ALMEIDA, F.A.; VAN VLECK, L.D.; GREGORY, K.E. Estimation of direct and maternal breed effects for prediction of expected progeny differences for birth and weaning weights in three multibreed populations. J. Anim. Sci., v.25, p.1203-1212, 1997.
SCHAEFFER, L.R. Tópicos avançados em melhoramento genético animal. Notas do Minicurso. DMGA/UNESP/Jaboticabal, 1996.

SMITH, S.P.; GRASER, H-U. Estimating variance components in a class of mixed models by restricted maximum likelihood. J. Dairy Sci., v.69, p.1156-1165, 1986.

TREMATORE, R.L.; ALENCAR, M.M.; BARBOSA, P.F. et al. Estimativas de efeitos aditivos e heteróticos para características de crescimento pré-desmama em bovinos CharolêsNelore. Rev. Bras. Zootec., v.27, p.87-94, 1998.

VENCOVSKY, R.; DIAS, O.J.; RICARDO, Y. Um modelo genético aplicado à análise de dados de produção de leite em gado bovino: relatório do departamento de genética. Piracicaba: ESALQ, 1970. p.130-136. 